\title{
Feeding Releases Endogenous Opioids in Humans
}

\author{
Jetro J. Tuulari, ${ }^{1,2,3 *}$ Lauri Tuominen, ${ }^{1,5 *}$ Femke E. de Boer, ${ }^{1}$ Jussi Hirvonen, ${ }^{1,6}$ Semi Helin, ${ }^{1}{ }^{-P}$ Pirjo Nuutila, ${ }^{1,7}$ \\ and (Dauri Nummenmaa ${ }^{1,4}$ \\ ${ }^{1}$ Turku PET Centre, ${ }^{2}$ Department of Psychiatry, Institute of Clinical Medicine, ${ }^{3}$ Turku Brain and Mind Center, and ${ }^{4}$ Department of Psychology, University of \\ Turku, 20520 Turku, Finland, ${ }^{5}$ Department of Psychiatry, Massachusetts General Hospital and Harvard Medical School, Boston, Massachusetts 02215, and \\ Departments of ${ }^{6}$ Radiology and ${ }^{7}$ Endocrinology, Turku University Hospital, 20521 Turku, Finland
}

The endogenous opioid system supports a multitude of functions related to appetitive behavior in humans and animals, and it has been proposed to govern hedonic aspects of feeding thus contributing to the development of obesity. Here we used positron emission tomography to investigate whether feeding results in hedonia-dependent endogenous opioid release in humans. Ten healthy males were recruited for the study. They were scanned with the $\mu$-opioid-specific ligand $\left[{ }^{11} \mathrm{C}\right]$ carfentanil three times, as follows: after a palatable meal, a nonpalatable meal, and after an overnight fast. Subjective mood, satiety, and circulating hormone levels were measured. Feeding induced significant endogenous opioid release throughout the brain. This response was more pronounced following a nonpalatable meal versus a palatable meal, and independent of the subjective hedonic responses to feeding. We conclude that feeding consistently triggers cerebral opioid release even in the absence of subjective pleasure associated with feeding, suggesting that metabolic and homeostatic rather than exclusively hedonic responses play a role in the feeding-triggered cerebral opioid release.

Key words: carfentanil; emotion; feeding; neuroreceptors; opioids; positron emission tomography

\section{Significance Statement}

The endogenous opioid system supports both hedonic and homeostatic functions. It has been proposed that overeating and concomitant opioid release could downregulate opioid receptors and promote the development of obesity. However, it remains unresolved whether feeding leads to endogenous opioid release in humans. We used in vivo positron emission tomography to test whether feeding triggers cerebral opioid release and whether this response is associated with pleasurable sensations. We scanned volunteers using the $\mu$-opioid receptor-specific radioligand $\left[{ }^{11} \mathrm{C}\right]$ carfentanil three times, as follows: after an overnight fast, after consuming a palatable meal, and after consuming a nonpalatable meal. Feeding led to significant endogenous opioid release, and this occurred also in the absence of feeding-triggered hedonia. Feeding-triggered opioid release thus also reflects metabolic and homeostatic responses rather than hedonic responses exclusively.

\section{Introduction}

Brain $\mu$-opioid receptor (MORs) system supports a multitude of functions related to appetitive behavior and food intake (Henriksen and Willoch, 2008; Pecina and Smith, 2010; Nummenmaa and Tuominen, 2017). In animals, activation of the MOR in the shell of nucleus accumbens increases pleasure responses for foods

Received March 28, 2017; revised July 6, 2017; accepted July 10, 2017.

Author contributions: L.T., J.H., P.N., and L.N. designed research; J.J.T., L.T., F.E.d.B., and S.H. performed research; J.T., L.T., and L.N. analyzed data; L.T., J.H., P.N., and L.N. wrote the paper.

The study was conducted within the Finnish Centre of Excellence in Cardiovascular and Metabolic Diseases and was supported by the Academy of Finland (Grants \#304385 and \#283320; and Grant \#251125to L.N.). J.J.T. was supported by a personal grant from the Finnish Cultural Foundation. We thank the staff of Turku PET Centre for their help with data collection.

*J.J.T. and L.T. contributed equally to this work.

The authors declare no competing financial interests.

Correspondence should be addressed to Lauri Nummenmaa, Turku PET Centre, c/0 Turku University Hospital, P.O. Box 52, 20520 Turku, Finland. E-mail: latanu@utu.fi.

DOI:10.1523/JNEUROSCI.0976-17.2017

Copyright $\odot 2017$ the authors $\quad 0270-6474 / 17 / 378284-08 \$ 15.00 / 0$ and may also trigger eating (Peciña and Berridge, 2005). In line with this, $\mu$-opioid receptor antagonists decrease and agonists increase food intake in both rodents and humans (Glass et al., 1999; Yeomans and Gray, 2002; Giuliano et al., 2012; Ziauddeen et al., 2013). Opioid receptor antagonists also decrease the pleasantness of the taste and smell of palatable foods in healthy volunteers (Yeomans and Wright, 1991), whereas inverse MOR agonists reduce the hedonic properties of food and eating (Nathan et al., 2012). Clinical evidence also shows that chronic opioid exposure is associated with increased sugar intake (Mysels and Sullivan, 2010). Accordingly, opiate addicts perceive sweetness as more pleasant than drug-naive control subjects, and this effect is reversible by opioid antagonists (Langleben et al., 2012; Green et al., 2013). Finally, MORs are also downregulated in individuals with morbid obesity and binge-eating disorder (Burghardt et al., 2015; Karlsson et al., 2015; Majuri et al., 2017), suggesting an opioidergic contribution in the development and maintenance of obesity. 
Animal studies have established that palatable food consumption leads to endogenous opioid release in the hypothalamus, anterior cingulate cortex, and nucleus accumbens (Dum et al., 1983; Colantuoni et al., 2001). Because weight loss normalizes initially downregulated MOR levels in obese humans, the downregulation in the obese state has been proposed to reflect prolonged overeating leading to perpetual overstimulation and concomitant downregulation of MORs (Burghardt et al., 2015; Karlsson et al., 2016). Yet in humans, the evidence for endogenous opioid release and its relation to hedonic aspects of feeding remains elusive. Positive mood has been reported to trigger endogenous opioid release in the amygdala (Koepp et al., 2009), and another early study reported that amphetamine-induced euphoric feelings correlated with increased endogenous opioid release (Colasanti et al., 2012), suggesting an association between opioidergic activity and hedonia. Subsequent studies have, however, failed to replicate this finding (Guterstam et al., 2013; Mick et al., 2014). More recently MOR availability has been shown to decrease immediately following a liquid meal (Burghardt et al., 2015), reflecting an increase in endogenous opioid levels. However, this study did not assess whether the opioid release reflected hedonic aspects of eating, or whether it is simply triggered by feeding per se.

If opioid release following feeding is related to the hedonic responses, pleasure caused by eating should increase opioid release in a dose-dependent manner. Consequently, endogenous opioid release following food consumption would be a candidate neurobiological mechanism that reinforces overeating in obese individuals. This hypothesis has far-reaching implications as novel treatments for overeating targeting the opioid system are developed, yet direct evidence for hedonia-related opioid release following food consumption is lacking in humans. Here we directly tested whether endogenous opioid release is related to the hedonic value of the consumed food. We used positron emission tomography (PET) with the MOR-specific ligand $\left[{ }^{11} \mathrm{C}\right]$ carfentanil to quantify the MOR availability following a (1) $12 \mathrm{~h}$ fast, (2) a palatable meal (high hedonic value), and (3) a nonpalatable meal (low hedonic value). We hypothesized that food consumption would lead to endogenous opioid release and that this response would be stronger following a palatable rather than a nonpalatable meal.

\section{Materials and Methods}

The study was conducted in accordance with the Declaration of Helsinki and was approved by the Ethical Committee of the Hospital District of South-Western Finland. Subjects gave written informed consent before participating in the measurements and were financially compensated for their participation in this study.

Subjects. Ten healthy males participated in the study (Table 1). They were recruited from the local student population in the Turku area via e-mail advertisements. Inclusion criteria were as follows: (1) male sex, (2) age 20-35 years, (3) native Finnish speaker with western Caucasian origin, and (4) body mass index (BMI) $18.5-25.0 \mathrm{~kg} / \mathrm{m}^{2}$. Only males were included in the sample because MOR availability differs between sexes (Zubieta et al., 1999). Exclusion criteria were as follows: (1) regular use of any medication; (2) recent weight changes of $>2 \mathrm{~kg}$ in 1 year; (3) prior or current psychiatric disorder including eating disorders; (4) expected poor compliance; (5) nicotine use; (6) excessive use of alcohol $(>20$ portions/month); (7) history of any drug abuse; (8) diabetes or disturbed glucose metabolism (fasting glucose level, $>6.0 \mathrm{mmol} / \mathrm{L}$; or glycated hemoglobin $\left(\mathrm{HbA}_{1 \mathrm{c}}\right)$ level, $\left.>6.0 \%\right)$; (9) past dose of radiation (from diagnostic imaging or prior research-related PET scans); and (10) presence of ferromagnetic objects contraindicating magnetic resonance imaging (MRI). Eligibility based on these criteria was determined during a screening visit consisting of somatic examination and the Structured Clinical Interview for DSM-IV Axis I Disorders (SCID-I) interview. Conductance-derived fat
Table 1. Subject characteristics, injected doses of radioactivity, and self-reported tastiness of the foods

\begin{tabular}{lcc}
\hline Subject characteristics & Mean & SD \\
\hline Age (years) & 22.4 & 1.6 \\
Weight (kg) & 77.1 & 8.2 \\
BMI (kg/m²) & 22.9 & 2.0 \\
Waist circumference (cm) & 84.1 & 8.5 \\
Waist-to-hip ratio & 0.8 & 0.04 \\
Fat percentage (\%) & 16.8 & 3.3 \\
Fasting glucose (mM) & 5.3 & 0.3 \\
HbA $_{1}$ (\%) & 4.9 & 0.2 \\
Total cholesterol (mM) & 4.1 & 0.7 \\
Triglycerides (mM) & 0.9 & 0.5 \\
TSH (mU/L) & 2.7 & 2.0 \\
Free $t_{(4)}$ (pmol/L) & 17.2 & 2.5 \\
Injected [11C]carfentanil doses & & \\
$\quad$ Fasting scans (MBq) & 257.0 & 12.1 \\
Palatable meal scans (MBq) & 248.5 & 10.5 \\
$\quad$ Nonpalatable meal scans (MBq) & 250.0 & 9.1 \\
Self-reported tastiness of the foods & & \\
$\quad$ Palatable meal & 8.4 & 0.5 \\
$\quad$ Nonpalatable meal & 3.8 & 2.0 \\
\hline
\end{tabular}

TSH, Thyroid-stimulating hormone.

percentages were measured with the Omron BF 400-E scale (Omron Healthcare Europe). Because the palatable meal consisted of pizza, the subject candidates were also briefly questioned regarding their meal preferences, and those expressing a dislike for pizza were not enrolled in the study.

Experimental design. The study was run using a within-subjects design with the following three PET scan conditions: fasting, palatable food (pizza) consumption, and nonpalatable liquid meal (nutrient drink) consumption. Scans were performed on separate days within a 3-4 week period and always at the same time of the day for a single participant, either in the morning (8:00 to 9:00 A.M.) or in the afternoon (12:00 to 13:00 P.M.). The order of the conditions was counterbalanced across participants. Before each visit, participants refrained from eating for 12-14 h (overnight fast) and were asked to avoid physical and mental stress and sexual interaction for $2 \mathrm{~d}$. Alcohol consumption was not allowed during the study period. All testing sessions begun with the placing of an intravenous catheter in the antecubital vein for radioligand injection and blood sampling for $\sim 60$ min before the scans.

In the fasting condition, subjects were scanned after a 40 min resting period, while in the palatable and nonpalatable meal conditions participants started pizza and diet coke consumption $20 \mathrm{~min}$ before the scheduled start of the PET scan. The 20 min time frame was based on a pilot study confirming that $20 \mathrm{~min}$ was sufficient for completing the meals. To ensure that hedonic properties of the pizza matched with individual preferences, the subjects chose their preferred pizza from three predetermined topping combinations from a pizza chain (Kotipizza), which makes each pizza with standardized recipe and ingredients. The pizza was served warm. Caloric content, carbohydrates, fat, other nutrients, and the number of calories (1040-1100 kcal per serving; $\sim 50 \mathrm{~g}$ of protein, $84 \mathrm{~g}$ of carbohydrates, $63 \mathrm{~g}$ of fat, and $6 \mathrm{~g}$ of salt) were matched as closely as possible between the pizzas and the nutritional drink (see below). The subjects also consumed a $0.5 \mathrm{~L}$ soft drink (Coca-Cola Light; $2 \mathrm{kcal},<0.1$ $\mathrm{g}$ protein, $0 \mathrm{~g}$ carbohydrates, and $0 \mathrm{~g}$ fat). The nutritional drink was made from pure carbohydrate, whey protein flour, canola oil, and salt (1108 $\mathrm{kcal}$ of energy, $69.8 \mathrm{~g}$ of protein, $84 \mathrm{~g}$ of carbohydrates, $63 \mathrm{~g}$ of fat, and $6 \mathrm{~g}$ of salt). The raw ingredients were measured with per-gram precision with a standard kitchen scale. The total volume of the nutritional drink was $0.9 \mathrm{~L}$, matching the volume of pizza and the soda after chewing.

Participants reported their feelings of happiness, anxiety, pleasantness, hunger, irritability, nausea, thirst, and satiation on a visual analog scale $(0-5)$ upon arrival, as well as before and after each scan. Participants also rated the deliciousness, satiety levels, and food craving while consuming the meals. 
Laboratory measurements. Plasma samples were obtained before the meals and after the PET scan via an antecubital catheter that was used for radioligand injections. Plasma glucose and insulin levels were measured upon arrival as a control to ensure that the subjects had fasted as instructed. On the day of the fasting scan, the blood samples were taken only once. On meal consumption scans, the plasma samples were taken immediately before eating and after the scans (20 and $51 \mathrm{~min}$ after the first sample). Glucose and insulin samples were analyzed on site by laboratory technicians using routine procedures. Ghrelin, glucagon-like peptide-1 (GLP-1), peptide YY (PYY), and leptin samples were processed after mixing the sample with an enzyme inhibitor cocktail to be able to measure active portions of the gastrointestinal hormones. The samples were frozen and stored before the analysis (below $-70^{\circ} \mathrm{C}$ ). The sample processing and analysis was performed using the provided instructions of the laboratory kit (MILLIPLEXmap Kit: Human Metabolic Hormone Magnetic Bead Panel, HMHEMAG-34K, Merck Millipore). We were able to obtain the ghrelin, GLP-1, PYY, and leptin measurements from only 6 of 10 participants due to the unexpected delivery problems of the enzyme inhibitor cocktails at the beginning of the study.

PET data acquisition and preprocessing. Data were acquired as described previously (Karlsson et al., 2015). Briefly, MOR availability was measured with the high-affinity agonist radioligand $\left[{ }^{11} \mathrm{C}\right]$ carfentanil (Frost et al., 1985), which has high test-retest reliability (Hirvonen et al., 2009). The radioligand was produced as described earlier (Karlsson et al., 2015), except that the mobile phase was altered to $\mathrm{CH}_{3} \mathrm{OH} / 0.1 \mathrm{M}$ $\mathrm{NH}_{4} \mathrm{HCO}_{2}$ (70:30). After intravenous radioligand injection, radioactivity in the brain was recorded with the GE Healthcare Discovery 690 $\mathrm{PET} /$ computed tomography scanner for $51 \mathrm{~min}$ with an in-plane resolution of $3.75 \mathrm{~mm}$ [effective resolution, $4.7 \mathrm{~mm}$ full-width at halfmaximum (FWHM)], using 13 frames of increasing duration $(3 \times 1 \mathrm{~min}$, $4 \times 3 \mathrm{~min}, 6 \times 6 \mathrm{~min})$. The injected radioligand doses were similar across the scans (Table 1). During scanning, participants were lying in a supine position with their heads gently strapped to the scanner table to limit head movement. Participants were monitored throughout the scan. Researchers ensured wakefulness by regular visits to the scanner room. T1-weighted anatomical MR reference images $\left(1 \mathrm{~mm}^{3}\right.$ voxel size $)$ were acquired with a Philips Ingenuity TF PET/MR 3 T (TR, 8.1 ms; TE, 3.7 $\mathrm{ms}$; flip angle, $7^{\circ}$; scan time, $263 \mathrm{~s}$ ).

Data were preprocessed with SPM12 (http://www.fil.ion.ucl.ac.uk/ spm/software/) running on Matlab 2014b for Mac (MathWorks). To account for head movements, the images of the first scan session were coregistered to the eighth frame of that session and summed. Subsequently, all PET images were realigned to the produced the summed image. Each subject's T1-weighted MR image was coregistered to the mean PET images. Occipital cortex was drawn manually on the MRI images using PMOD version 3.4 software (PMOD Technologies). Receptor availability was expressed in terms of $\mathrm{BP}_{\mathrm{ND}}$, which is the ratio of specific to nondisplaceable binding in the brain. Occipital cortex was used as the reference region, as it is practically devoid of MOR (Hiller and Fan, 1996). $\mathrm{BP}_{\mathrm{ND}}$ was calculated for each voxel with PMOD version 3.4 using the simplified reference tissue model with reference-tissue time activity curves as input data (Gunn et al., 1997). This outcome measure is not confounded by blood flow or radioligand transport (Sander et al., 2014). Subject-wise parametric $\mathrm{BP}_{\mathrm{ND}}$ images were normalized to the MNI space using the transformation matrices obtained from the normalization of the T1-weighted MR images. Finally, 8 mm FWHM Gaussian smoothing was applied.

Statistical analysis. The study was run using a fully within-subjects design. Voxelwise differences in MOR availability were analyzed using SPM12 using directed $t$ contrasts, as follows: fast $>$ nonpalatable meal, fast $>$ palatable meal, and palatable meal $>$ nonpalatable meal, as well as the opposite contrasts. Statistical threshold was set at $p<0.05$, false discovery rate (FDR) corrected at cluster level $(p<0.05)$. In a complementary methodological approach, anatomical regions of interest (ROIs) were automatically generated in the ventral striatum, caudate nucleus, putamen, insula, amygdala, thalamus, orbitofrontal cortex, anterior cingulate cortex, middle cingulate cortex, and posterior cingulate cortex using the Anatomy and AAL toolboxes (Tzourio-Mazoyer et al.,
2002; Eickhoff et al., 2005). Subsequently, condition-wise $\mathrm{BP}_{\mathrm{ND}}$ values were extracted for each subject and ROI using the Marsbar toolbox (http://marsbar.sourceforge.net/download.html). Behavioral, biologi$\mathrm{cal}$, and ROI data were analyzed with SPSS Statistics version 22 for Mac OS X (IBM). The normality assumption was tested with a Shapiro-Wilk test. We used an appropriate repeated-measures ANOVA to investigate the changes of the binding potentials and other measures within and between scan sessions. Within the ANOVA models, nonsphericity was estimated with Mauchley's test, and when the criteria were not met, the Greenhouse-Geisser correction was applied.

\section{Results}

\section{Self-reports and laboratory measures}

Self-reports and laboratory measures are summarized in Figure 1 and Table 2. During feeding, the palatable meal (pizza) was consistently rated more tasty than the nonpalatable meal ( 8.4 vs 3.8; $\left.t_{(9)}=8.70, p<0.001\right)$. Accordingly, pleasure ratings were comparable before eating the palatable versus the nonpalatable meals $(t=-0.75, p=0.47)$ but differed at the beginning of the PET scans following food consumption $\left(F_{(2,20)}=5.116, p=0.02, \eta_{\mathrm{p}}^{2}=0.36\right)$. Pleasure ratings were higher for palatable versus nonpalatable foods and for fast versus nonpalatable foods ( $p$ values $<0.05$ ). Again, no differences were found after the scan $\left(F_{(2,20)}=0.46\right.$, $p=0.64)$. Satiety was comparable before eating the palatable versus nonpalatable meals $(t=0.45, p=0.67)$ but differed at the beginning of the PET scans following food consumption $\left(F_{(2,20)}=\right.$ 57.58, $\left.p<0.01, \eta_{\mathrm{p}}^{2}=0.88\right)$. Both immediately after the meal as well as after the PET scan, satiety was higher following the palatable and nonpalatable meal versus fasting ( $p$ values $<0.001$ ), but, importantly, there were no differences between the palatable and nonpalatable meal conditions $(t=1.81, p=0.10)$. Plasma insulin $\left(F_{(1,7)}=26.32, p<0.001, \eta_{\mathrm{p}}^{2}=0.79\right), \mathrm{GLP}-1\left(F_{(1,5)}=23.04, p=\right.$ $\left.0.005, \eta_{\mathrm{p}}^{2}=0.82\right)$, ghrelin $\left(F_{(1,5)}=6.14, p=0.05, \eta_{\mathrm{p}}^{2}=0.58\right)$, and $\operatorname{PYY}\left(F_{(1,5)}=15.39, p=0.01, \eta_{\mathrm{p}}^{2}=0.76\right)$ concentrations increased postprandially. However, there were no significant food type $\times$ measurement time interactions ( $F$ values $<2.55$, $p$ values $>0.16$ ). Plasma glucose and leptin levels were comparable across conditions and were not influenced by food consumption $(F$ values $<2.92$, $p$ values $>0.15)$.

\section{$\boldsymbol{\mu}$-Opioid binding potentials}

Full-volume analysis revealed that the consumption of both palatable (pizza) and nonpalatable meals triggered widespread endogenous opioid release (reflected in decreased $\left[{ }^{11} \mathrm{C}\right]$ carfentanil $\mathrm{BP}_{\mathrm{ND}}$ ) in comparison with the baseline fasting scan (Fig. 2). Nonpalatable food consumption caused a global $\mathrm{BP}_{\mathrm{ND}}$ decrease compared with fasting scans (Fig. 2, left). Palatable food consumption versus fasting state also decreased MOR binding, but in a more limited number of regions including caudate nucleus, thalamus, and cingulate cortex (Fig. 2, middle). Direct comparisons between nonpalatable versus palatable meal conditions revealed that decreases in $\mathrm{BP}_{\mathrm{ND}}$ values were significantly larger following the nonpalatable meal condition (Fig. 2, right).

These effects were corroborated by a complementary ROI analysis. In a 3 (condition: fast, palatable meal, nonpalatable meal $) \times 10($ ROI $)$ repeated-measures ANOVA, we found a main effect of condition $\left(F_{(2,22)}=9.81, p<0.001, \eta_{p}^{2}=0.47\right)$, reflecting $\mathrm{BP}_{\mathrm{ND}}$ changes across the nonpalatable food versus fasting condition $(p<0.001)$ and marginally for the palatable food versus fasting condition $(p=0.056)$, as well as a main effect of ROI $\left(F_{(9,198)}=78.64, p<0.001, \eta_{\mathrm{p}}^{2}=0.87\right)$, resulting from regional differences in MOR availability. These effects were qualified by a condition $\times$ ROI interaction $\left(F_{(18,198)}=5.71, p<0.001, \eta_{\mathrm{p}}^{2}=\right.$ $0.34)$. ROI-wise contrast tests revealed that binding potentials 

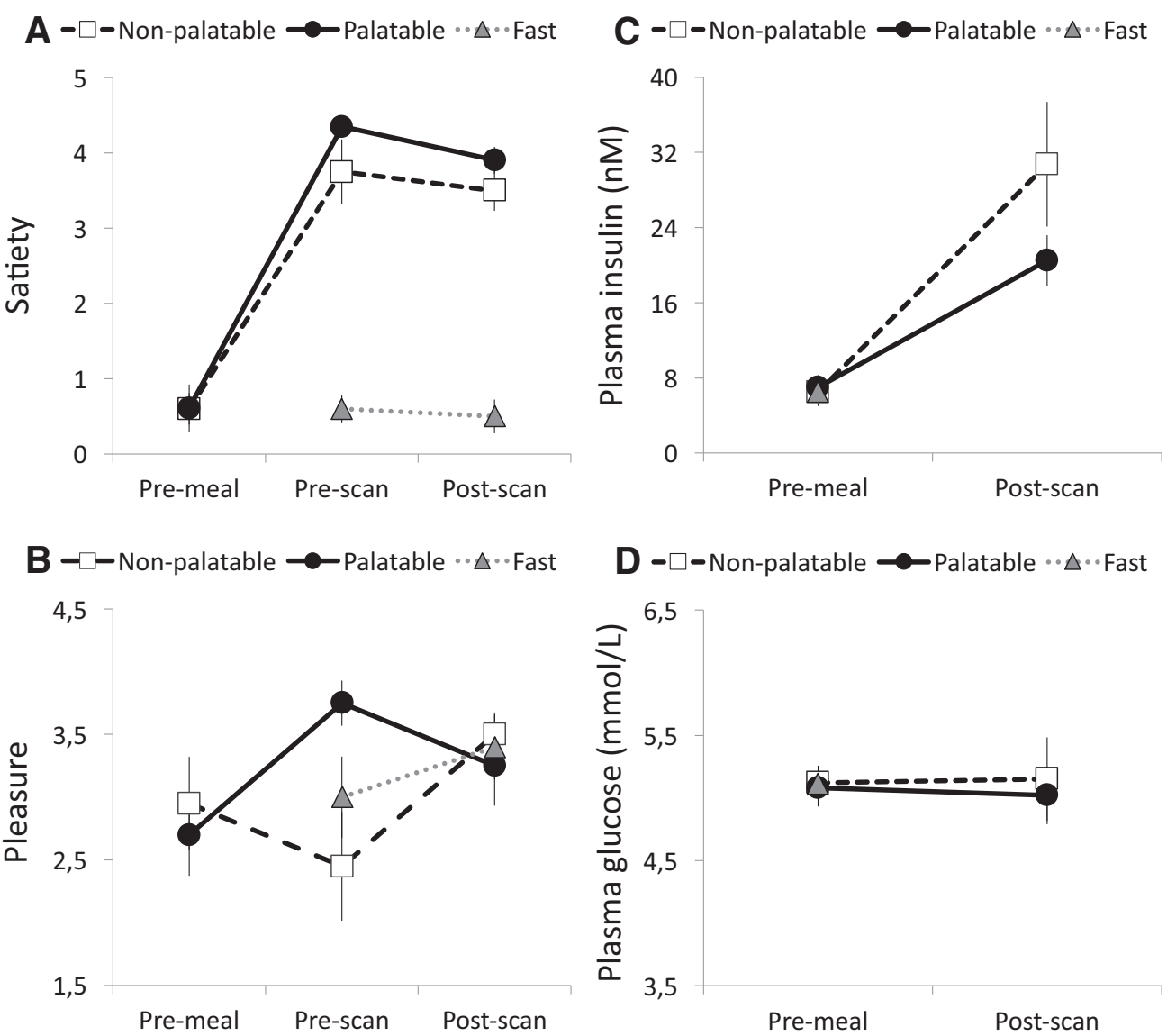

Figure 1. Behavioral ratings and laboratory measurements. $\boldsymbol{A}, \boldsymbol{B}$, Mean subjective ratings for satiety $(\boldsymbol{A})$ and pleasure $(\boldsymbol{B})$ before meal, before scan, and after scan. $\boldsymbol{C}, \boldsymbol{D}$, Mean plasma insulin $(\boldsymbol{C})$ and glucose $(\boldsymbol{D})$ levels before the meal and after the scans. Error bars show the SEM.

Table 2. Laboratory measurements before and after the meals

\begin{tabular}{lrrrrr}
\hline & \multicolumn{2}{c}{ Palatable meal } & & \multicolumn{2}{c}{ Nonpalatable meal } \\
\cline { 2 - 3 } & Mean & SD & & Mean & SD \\
\hline Premeal glucose (mmol/L) & 5.1 & 0.4 & & 5.1 & 0.4 \\
Postmeal glucose (mmol/L) & 5.0 & 0.7 & & 5.2 & 1.0 \\
Premeal insulin (mU/L) & 6.6 & 3.9 & & 6.5 & 4.5 \\
Postmeal insulin (mU/L) & 20.5 & 8.1 & & 30.8 & 19.9 \\
Premeal ghrelin (pg/ml) & 42.2 & 26.7 & 31.2 & 13.5 \\
Postmeal ghrelin (pg/ml) & 26.8 & 11.9 & & 22.3 & 8.0 \\
Premeal GLP-1 (pmol/L) & 2.7 & 0.0 & & 2.7 & 0.0 \\
Postmeal GLP-1 (pmol/L) & 15.3 & 9.5 & & 16.1 & 10.9 \\
Premeal leptin (ng/ml) & 1.9 & 0.3 & & 1.9 & 2.7 \\
Postmeal leptin (ng/ml) & 2.1 & 3.5 & & 1.8 & 2.7 \\
Premeal PYY (pg/ml) & 75.3 & 43.4 & & 59.2 & 30.6 \\
Postmeal PYY (pg/ml) & 94.3 & 49.4 & 85.5 & 44.6 \\
\hline
\end{tabular}

exhibited a clear pattern of fast $>$ palatable meal $>$ nonpalatable meal (Fig. 3). MOR binding decreased in all ROIs following nonpalatable meal versus fasting state conditions. For palatable meal versus fast, a significant effect was observed in dorsal caudate nucleus. $\mathrm{BP}_{\mathrm{ND}}$ values decreased more following nonpalatable versus palatable meal in all ROIs $(p$ values $<0.05)$ except amygdala.

Finally, we tested whether food consumption-triggered regional $\mathrm{BP}_{\mathrm{ND}}$ changes would be associated with pleasantness ratings with foods. However, these effects were not statistically significant in either condition (palatable or nonpalatable meal) in any region.

\section{Discussion}

Our main finding was that consuming both palatable and nonpalatable meals led to widespread endogenous opioid release in the brain. These effects were observed in large clusters, with peaks in the ventral striatum, thalamus, and anterior cingulate cortex. Opioid release was significantly stronger following the nonpalatable versus palatable meal, and it was independent of the subjective hedonic value of food. Consequently, even the consumption of nonpalatable foods may lead to significant postprandial endogenous opioid release in the absence of concomitant hedonic response, even though hedonia associated with feeding may also contribute to the response (Dum et al., 1983; Colantuoni et al., 2001).

\section{Feeding triggers opioid release independently of hedonia}

A prominent hypothesis proposes that the brain opioid system encodes the "liking" component (i.e., the hedonic reaction) of the reward processing (Berridge, 2009; Berridge et al., 2010), and previous PET studies in humans have linked the human endogenous opioid system with variety of mood and hedonic functions (Zubieta et al., 2001; Koepp et al., 2009; Nummenmaa et al., 2016). Consequently, it has been proposed that altered opioidergic functions in conditions involving overeating would reflect alterations in hedonic processing (Burghardt et al., 2015; Karlsson et al., 2015). Our findings on postprandial opioid release accord with the general role of opioids in feeding (Pecina and Smith, 2010) and suggest that repeated feeding-triggered opioid release is a possible mechanism leading to MOR downregulation in obesity. The effects were also consistent across the studied individuals $(n=10)$. 


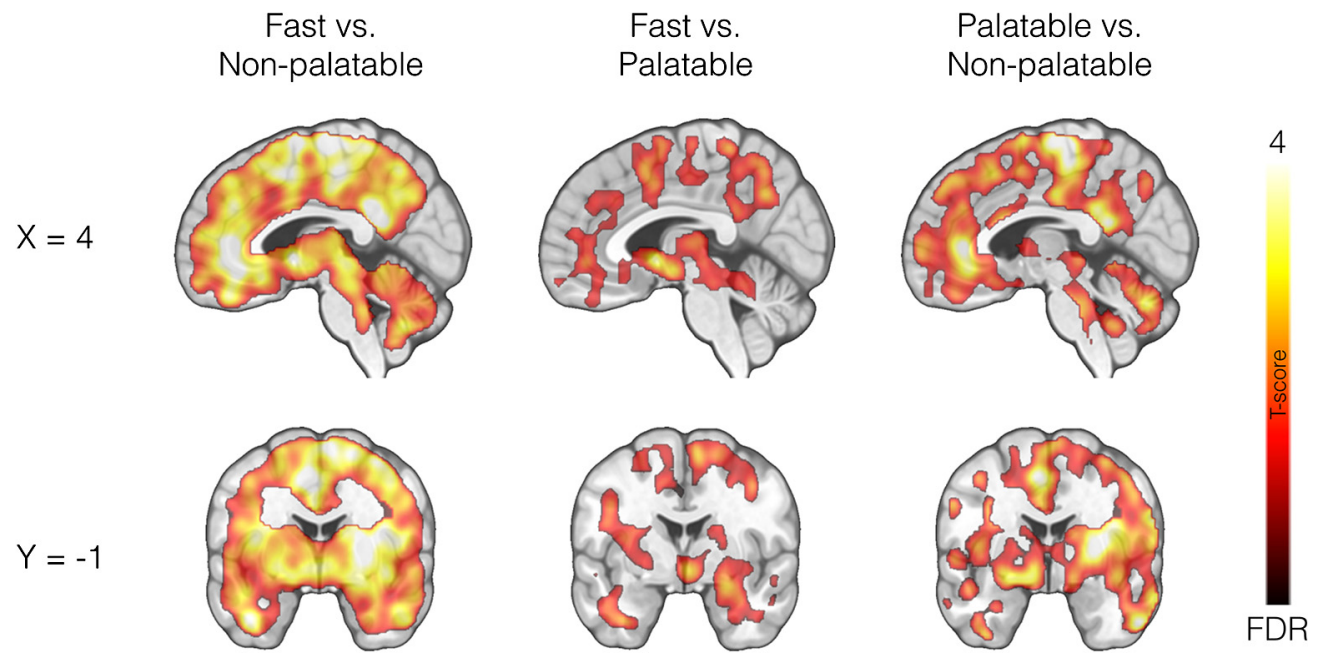

Figure 2. Full-volume analysis. Brain regions where $\left[{ }^{11} \mathrm{C}\right]$ carfentanil $\mathrm{BP}_{\mathrm{ND}}$ values were different between fasting and the nonpalatable meal (left), fasting and the palatable meal (middle), and the palatable meal and the nonpalatable meal (right). The data are thresholded at $p<0.05$, FDR corrected at cluster level. The color bar shows the $t$ statistic range.

In ventral striatum, feeding-induced opioid release was observed in 10 of 10 subjects in the nonpalatable meal condition and in 7 of 10 subjects in the palatable meal condition; furthermore, the difference between nonpalatable and palatable meals was significant in 7 of 10 subjects. The corresponding effect sizes (Cohen's d) were $>1.39$, exceeding the conventional limit (0.8) for a large effect (Cohen, 1992).

Against our expectations, the present study did not reveal an association between MOR activation and hedonic aspects of feeding. Both palatable and nonpalatable meals induced significant changes in MOR activity, while only palatable meal consumption induced subjective pleasurable sensations. However, we found that the opioid release was stronger following the nonpalatable meal than the palatable meal, despite careful matching of the energy content and nutrients in the meals and no differences in subjective (selfreport) and hormonal (plasma insulin, GLP-1, ghrelin, and PYY levels) measures of satiety, as well as using a subjectively preferred palatable meal whose feeding has been found to be modulated by the opioid system in preclinical studies (for a review, see Gosnell and Levine, 2009). No association between endogenous opioid release and self-reported pleasure could be established (although this may also reflect the limited sample size), which accords with some prior studies showing decoupling between endogenous opioid levels and acute mood changes (Guterstam et al., 2013; Mick et al., 2014; Burghardt et al., 2015). Thus, the present evidence suggests that a mere change in the energy homeostasis following feeding is enough to trigger endogenous opioid release in humans. Rewarding aspects of feeding may contribute to the opioid release independently of the homeostatic response, but the present study

\section{Non-palatable meal \\ Palatable meal \\ Fast}

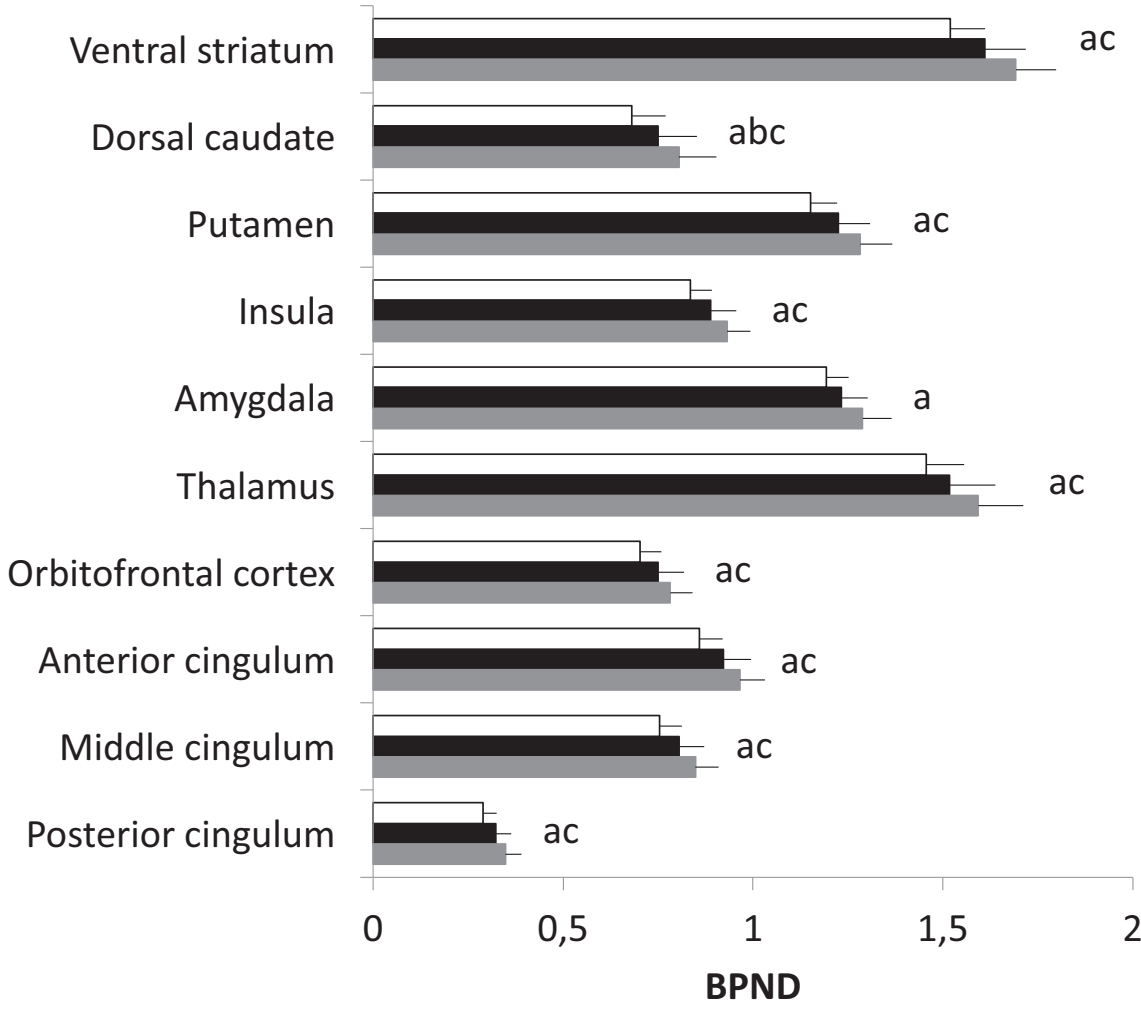

Figure 3. Region-of-interest analysis. Means and $\mathrm{SEs}$ of mean for regional binding potentials (i.e., $\mathrm{BP}_{\mathrm{ND}}$ values) in the nonpalatable meal, the palatable meal, and fasting conditions. Letters indicate significant differences $(p<0.05)$ in the one-way contrasts between fast $>$ nonpalatable meal (a), fast $>$ palatable meal (b), and palatable meal $>$ nonpalatable meal (c).

cannot directly disentangle the relative magnitudes of the two effects.

A possible reason for these discrepancies is that whereas prior preclinical and clinical studies have upregulated or downregulated the MOR system pharmacologically, we instead measured feeding-triggered endogenous opioid release directly in vivo. The observed MOR activation may indeed be influenced by numerous factors other than the hedonic response of feeding (for a review, see Nummenmaa and Tuominen, 2017). One possible 
explanation for the larger opioid release following the nonpalatable meal is that the nonpalatable liquid meal was digested faster in both the stomach and intestine, thus resulting in faster humoral and neural gastrointestinal responses. Consequently, the faster coupling between plasma nutrients and circulating hormones may cause opioid release in the brain via hypothalamusmediated mechanisms. Regardless of what mechanism ultimately underlies the eating-dependent endogenous opioid release, these results suggest that repeated stimulation of the MOR system due to overeating can potentially lead to its downregulation, as speculated in prior studies (Karlsson et al., 2015, 2016). However, even though eating itself would not always lead to hedonia-dependent changes in opioid release (e.g., in the case of nonpalatable food consumption), it is possible that the MOR downregulation following repeated overeating can lead to alterations in mood. Accordingly, one prior study (Karlsson et al., 2015) has found that MOR availability was associated with trait anxiety in the morbidly obese subjects, suggesting that the interaction between feeding and mood may be mediated by MOR.

All in all, our results suggest that the relationship among opioids, feeding, and pleasure may be more complex than previously thought. Even though opioid agonists and antagonists increase and decrease food intake, respectively (Glass et al., 1999; Yeomans and Gray, 2002; Mysels and Sullivan, 2010; Giuliano et al., 2012; Ziauddeen et al., 2013), the effects of $\mu$-opioid agonists in subjective hedonic feelings in drug-naive subjects are much more variable (Lasagna et al., 1955; Tedeschi et al., 1984; Zacny and Gutierrez, 2003, 2009; Riley et al., 2010; Ipser et al., 2013). Together with mixed evidence on endogenous opioid release during positive moods in imaging studies (Boecker et al., 2008; Koepp et al., 2009; Burghardt et al., 2015; Manninen et al., 2017; Nummenmaa and Tuominen, 2017), these data call for a more detailed investigation of the specific contribution of opioids in affective and homeostatic processes in humans.

It must be noted that rewarding and motivating effects of foods likely also act via other neurotransmitter systems, in particular the dopaminergic system, which interacts intimately with the opioidergic system (Tuominen et al., 2015). In line with this, orally consumed foods trigger significant dopamine release in the striatum (Small et al., 2003), yet similar effects are not observed with intravenously administered glucose (Haltia et al., 2007, 2008). Consequently, the actual process of consuming the food (rather than the concomitant changes in blood glucose levels) might also be critical for the activity changes in the reward system. It is thus possible that the dopamine system is critical for the rewarding aspects of feeding, whereas the opioid release observed in the present study would be triggered by more general-level homeostatic signaling (Nogueiras et al., 2012).

Face-to-face individual treatment of obesity is very labor intensive and costly, and, unfortunately, the conventional dietingbased approach for weight loss has a low success rate (Anderson et al., 2001). Alterations in the opioid system that controls food intake (Karlsson et al., 2015) may be partly responsible for maintaining unhealthy eating habits. The present data provide further evidence that opioid blockage might be an effective way for preventing overeating and promoting weight loss in humans by blocking the effects of feeding-induced opioid release. Indeed, opioid antagonists also prevent food seeking and binge-like eating (Giuliano et al., 2012; Cambridge et al., 2013). Similarly, it has been established that weight loss by dieting or by surgical means normalizes MORs in morbidly obese subjects (Burghardt et al., 2015; Karlsson et al., 2015), suggesting that both acute and chronic alterations in the opioidergic system contribute to feeding preferences.

\section{Methodological considerations}

We studied only healthy young males, so it remains unknown whether these results generalize to females and other age groups. The PET technique does not allow disentangling whether the $\mathrm{BP}_{\mathrm{ND}}$ changes reflect receptor internalization, altered conformation, or occupancy by endogenous neurotransmitter. Therefore, we cannot specify which interpretation is most appropriate. Nonetheless, all of these changes are thought to reflect endogenous opioid release. Additionally, using the current protocol we cannot disentangle the exact time course of the MOR activation changes. As the subjects were scanned $\sim 15$ min after the meal, it is possible that the peak effect of nonpalatable meal was reached sooner than that for the palatable meal, yielding higher $\mathrm{BP}_{\mathrm{ND}}$ values during the 51-min measurement.

Serving subject-chosen pizza allowed matching the palatable meal with subject preferences (Small et al., 2003), whereas the liquid meal provided a compromised macronutrient and volumematched nonpalatable control. While resembling everyday food consumption, this design has two limitations. First, chewing (required for pizza) could also influence the hedonic and homeostatic responses of food on the brain (Higgs and Jones, 2013). Second, the liquid meal may have led to faster humoral and neural gastrointestinal responses, thus triggering more profound opioid release. After this initial demonstration with natural feeding conditions, future studies could compare opioid release following directly matched palatable versus nonpalatable meals such as milkshake (Stice et al., 2008) to provide a finer grained analysis of the effects of mere palatability of foods on opioid release under a controlled setting. Nevertheless, we stress that neither of these limitations counter our argument that feeding may trigger opioid release in the absence of hedonia.

\section{Conclusions}

We conclude that food consumption causes a robust and widespread cerebral opioid release in comparison with the fasted state. Nonpalatable liquid nutrition, however, caused stronger opioidergic responses than palatable pizza, thus the observed effects do not reflect the hedonic properties of the meal. These data highlight the role of the endogenous opioid system in human feeding but suggest that the opioidergic system contributes to feeding even in the absence of hedonia.

\section{References}

Anderson JW, Konz EC, Frederich RC, Wood CL (2001) Long-term weightloss maintenance: a meta-analysis of US studies. Am J Clin Nutr 74:579_ 584. Medline

Berridge KC (2009) "Liking" and "wanting" food rewards: brain substrates and roles in eating disorders. Physiol Behav 97:537-550. CrossRef Medline

Berridge KC, Ho CY, Richard JM, DiFeliceantonio AG (2010) The tempted brain eats: pleasure and desire circuits in obesity and eating disorders. Brain Res 1350:43-64. CrossRef Medline

Boecker H, Sprenger T, Spilker ME, Henriksen G, Koppenhoefer M, Wagner KJ, Valet M, Berthele A, Tolle TR (2008) The runner's high: opioidergic mechanisms in the human brain. Cereb Cortex 18:2523-2531. CrossRef Medline

Burghardt PR, Rothberg AE, Dykhuis KE, Burant CF, Zubieta JK (2015) Endogenous opioid mechanisms are implicated in obesity and weight loss in humans. J Clin Endocrinol Metab 100:3193-3201. CrossRef Medline

Cambridge VC, Ziauddeen H, Nathan PJ, Subramaniam N, Dodds C, Chamberlain SR, Koch A, Maltby K, Skeggs AL, Napolitano A, Farooqi IS, Bullmore ET, Fletcher PC (2013) Neural and behavioral effects of a novel mu opioid receptor antagonist in binge-eating obese people. Biol Psychiatry 73:887-894. CrossRef Medline 
Cohen J (1992) A power primer. Psychol Bull 112:155-159. CrossRef Medline Colantuoni C, Schwenker J, McCarthy J, Rada P, Ladenheim B, Cadet JL, Schwartz GJ, Moran TH, Hoebel BG (2001) Excessive sugar intake alters binding to dopamine and mu-opioid receptors in the brain. Neuroreport 12:3549-3552. CrossRef Medline

Colasanti A, Searle GE, Long CJ, Hill SP, Reiley RR, Quelch D, Erritzoe D, Tziortzi AC, Reed LJ, Lingford-Hughes AR, Waldman AD, Schruers KR, Matthews PM, Gunn RN, Nutt DJ, Rabiner EA (2012) Endogenous opioid release in the human brain reward system induced by acute amphetamine administration. Biol Psychiatry 72:371-377. CrossRef Medline

Dum J, Gramsch C, Herz A (1983) Activation of hypothalamic betaendorphin pools by reward induced by highly palatable food. Pharmacol Biochem Behav 18:443-447. Medline

Eickhoff SB, Stephan KE, Mohlberg H, Grefkes C, Fink GR, Amunts K, Zilles K (2005) A new SPM toolbox for combining probabilistic cytoarchitectonic maps and functional imaging data. Neuroimage 25:1325-1335. CrossRef Medline

Frost JJ, Wagner HN Jr, Dannals RF, Ravert HT, Links JM, Wilson AA, Burns HD, Wong DF, McPherson RW, Rosenbaum AE (1985) Imaging opiate receptors in the human brain by positron tomography. J Comput Assist Tomogr 9:231-236. CrossRef Medline

Giuliano C, Robbins TW, Nathan PJ, Bullmore ET, Everitt BJ (2012) Inhibition of opioid transmission at the mu-opioid receptor prevents both food seeking and binge-like eating. Neuropsychopharmacology 37:26432652. CrossRef Medline

Glass MJ, Billington CJ, Levine AS (1999) Opioids and food intake: distributed functional neural pathways? Neuropeptides 33:360-368. CrossRef Medline

Gosnell BA, Levine AS (2009) Reward systems and food intake: role of opioids. Int J Obes (Lond) (2005) 33 [Suppl 2]:S54-S58. CrossRef Medline

Green A, Kaul A, O'Shea J, Sharma E, Bennett L, Mullings EL, Munafò MR, Nutt DJ, Melichar JK, Donaldson LF (2013) Opiate agonists and antagonists modulate taste perception in opiate-maintained and recently detoxified subjects. J Psychopharmacol 27:265-275. CrossRef Medline

Gunn RN, Lammertsma AA, Hume SP, Cunningham VJ (1997) Parametric imaging of ligand-receptor binding in PET using a simplified reference region model. Neuroimage 6:279-287. CrossRef Medline

Guterstam J, Jayaram-Lindström N, Cervenka S, Frost JJ, Farde L, Halldin C, Franck J (2013) Effects of amphetamine on the human brain opioid system-a positron emission tomography study. Int J Neuropsychopharmacol 16:763-769. CrossRef Medline

Haltia LT, Rinne JO, Merisaari H, Maguire RP, Savontaus E, Helin S, Nagren K, Kaasinen V (2007) Effects of intravenous glucose on dopaminergic function in the human brain in vivo. Synapse (New York) 61:748-756. CrossRef Medline

Haltia LT, Rinne JO, Helin S, Parkkola R, Nagren K, Kaasinen V (2008) Effects of intravenous placebo with glucose expectation on human basal ganglia dopaminergic function. Synapse (New York) 62:682-688. CrossRef Medline

Henriksen G, Willoch F (2008) Imaging of opioid receptors in the central nervous system. Brain 131:1171-1196. CrossRef Medline

Higgs S, Jones A (2013) Prolonged chewing at lunch decreases later snack intake. Appetite 62:91-95. CrossRef Medline

Hiller JM, Fan LQ (1996) Laminar distribution of the multiple opioid receptors in the human cerebral cortex. Neurochem Res 21:1333-1345. CrossRef Medline

Hirvonen J, Aalto S, Hagelberg N, Maksimow A, Ingman K, Oikonen V, Virkkala J, Någren K, Scheinin H (2009) Measurement of central muopioid receptor binding in vivo with PET and [11C]carfentanil: a testretest study in healthy subjects. Eur J Nucl Med Mol Imaging 36:275-286. CrossRef Medline

Ipser JC, Terburg D, Syal S, Phillips N, Solms M, Panksepp J, Malcolm-Smith S, Thomas K, Stein DJ, van Honk J (2013) Reduced fear-recognition sensitivity following acute buprenorphine administration in healthy volunteers. Psychoneuroendocrinology 38:166-170. CrossRef Medline

Karlsson HK, Tuominen L, Tuulari JJ, Hirvonen J, Parkkola R, Helin S, Salminen P, Nuutila P, Nummenmaa L (2015) Obesity is associated with decreased mu-opioid but unaltered dopamine D-2 receptor availability in the brain. J Neurosci 35:3959-3965. CrossRef Medline

Karlsson HK, Tuulari JJ, Tuominen L, Hirvonen J, Honka H, Parkkola R,
Helin S, Salminen P, Nuutila P, Nummenmaa L (2016) Weight loss after bariatric surgery normalizes brain opioid receptors in morbid obesity. Mol psychiatry 21:1057-1062. CrossRef Medline

Koepp MJ, Hammers A, Lawrence AD, Asselin MC, Grasby PM, Bench CJ (2009) Evidence for endogenous opioid release in the amygdala during positive emotion. Neuroimage 44:252-256. CrossRef Medline

Langleben DD, Busch EL, O’Brien CP, Elman I (2012) Depot naltrexone decreases rewarding properties of sugar in patients with opioid dependence. Psychopharmacology (Berl) 220:559-564. CrossRef Medline

Lasagna L, Vonfelsinger JM, Beecher HK (1955) Drug-induced mood changes in man. 1. Observations on healthy subjects, chronically ill patients, and postaddicts. JAMA 157:1006-1020. CrossRef

Majuri J, Joutsa J, Johansson J, Voon V, Alakurtti K, Parkkola R, Lahti T, Alho H, Hirvonen J, Arponen E, Forsback S, Kaasinen V (2017) Dopamine and opioid neurotransmission in behavioral addictions: a comparative PET study in pathological gambling and binge eating. Neuropsychopharmacology 42:1169-1177. CrossRef Medline

Manninen S, Tuominen L, Dunbar RIM, Karjalainen T, Hirvonen J, Arponen E, Jääskeläinen IP, Hari R, Sams M, Nummenmaa L (2017) Social laughter triggers endogenous opioid release in humans J Neurosci 37:61256131. CrossRef Medline

Mick I, Myers J, Stokes PR, Erritzoe D, Colasanti A, Bowden-Jones H, Clark L, Gunn RN, Rabiner EA, Searle GE, Waldman AD, Parkin MC, Brailsford AD, Nutt DJ, Lingford-Hughes AR (2014) Amphetamine induced endogenous opioid release in the human brain detected with $[11 \mathrm{C}]$ carfentanil PET: replication in an independent cohort. Int J Neuropsychopharmacol 17:2069-2074. CrossRef Medline

Mysels DJ, Sullivan MA (2010) The relationship between opioid and sugar intake: review of evidence and clinical applications. J Opioid Manag 6:445-452. CrossRef Medline

Nathan PJ, O'Neill BV, Bush MA, Koch A, Tao WX, Maltby K, Napolitano A, Brooke AC, Skeggs AL, Herman CS, Larkin AL, Ignar DM, Richards DB, Williams PM, Bullmore ET (2012) Opioid receptor modulation of hedonic taste preference and food intake: a single-dose safety, pharmacokinetic, and pharmacodynamic investigation with GSK1521498, a novel mu-opioid receptor inverse agonist. J Clin Pharmacol 52:464474. CrossRef Medline

Nogueiras R, Romero-Picó A, Vazquez MJ, Novelle MG, López M, Diéguez C (2012) The opioid system and food intake: homeostatic and hedonic mechanisms. Obes Facts 5:196-207. CrossRef Medline

Nummenmaa L, Tuominen LJ (2017) Opioid system and human emotions. Br J Pharmacol. Advance online publication. Retrieved July 26, 2017. doi:10.1111/bph.13812. CrossRef Medline

Nummenmaa L, Tuominen L, Dunbar R, Hirvonen J, Manninen S, Arponen E, Machin A, Hari R, Jääskeläinen IP, Sams M (2016) Social touch modulates endogenous $\mu$-opioid system activity in humans. Neuroimage 138: 242-247. CrossRef Medline

Peciña S, Berridge KC (2005) Hedonic hot spot in nucleus accumbens shell: where do mu-opioids cause increased hedonic impact of sweetness? J Neurosci 25:11777-11786. CrossRef Medline

Pecina S, Smith KS (2010) Hedonic and motivational roles of opioids in food reward: implications for overeating disorders. Pharmacol Biochemi Behav 97:34-46. CrossRef

Riley JL 3rd, Hastie BA, Glover TL, Fillingim RB, Staud R, Campbell CM (2010) Cognitive-affective and somatic side effects of morphine and pentazocine: side-effect profiles in healthy adults. Pain Med 11:195-206. CrossRef Medline

Sander CY, Hooker JM, Wey HY, Wilson CM, Catana C, Rosen B, Mandeville JB (2014) Effects of simultaneously measured flow changes on D2/D3 radiotracer dynamics. Paper presented at 10th International Symposium on Functional Neuroreceptor Mapping of the Living Brain, Amsterdam, The Netherlands, May.

Small DM, Jones-Gotman M, Dagher A (2003) Feeding-induced dopamine release in dorsal striatum correlates with meal pleasantness ratings in healthy human volunteers. Neuroimage 19:1709-1715. CrossRef Medline

Stice E, Spoor S, Bohon C, Small DM (2008) Relation between obesity and blunted striatal response to food is moderated by TaqIA A1 allele. Science 322:449-452. CrossRef Medline

Tedeschi G, Smith AT, Richens A (1984) Effect of meptazinol and ethanol on human psychomotor performance and mood ratings. Hum Toxicol 3:37-43. CrossRef Medline

Tuominen L, Tuulari J, Karlsson H, Hirvonen J, Helin S, Salminen P, 
Parkkola R, Hietala J, Nuutila P, Nummenmaa L (2015) Aberrant mesolimbic dopamine-opiate interaction in obesity. Neuroimage 122:8086. CrossRef Medline

Tzourio-Mazoyer N, Landeau B, Papathanassiou D, Crivello F, Etard O, Delcroix N, Mazoyer B, Joliot M (2002) Automated anatomical labeling of activations in SPM using a macroscopic anatomical parcellation of the MNI MRI single-subject brain. Neuroimage 15:273-289. CrossRef Medline

Yeomans MR, Gray RW (2002) Opioid peptides and the control of human ingestive behaviour. Neurosci Biobehav Rev 26:713-728. CrossRef Medline

Yeomans MR, Wright P (1991) Lower pleasantness of palatable foods in nalmefene-treated human volunteers. Appetite 16:249-259. CrossRef Medline

Zacny JP, Gutierrez S (2003) Characterizing the subjective, psychomotor, and physiological effects of oral oxycodone in non-drug-abusing volunteers. Psychopharmacology (Berl) 170:242-254. CrossRef Medline

Zacny JP, Gutierrez S (2009) Within-subject comparison of the psychopharmacological profiles of oral hydrocodone and oxycodone combina- tion products in non-drug-abusing volunteers. Drug Alcohol Depend 101:107-114. CrossRef Medline

Ziauddeen H, Chamberlain SR, Nathan PJ, Koch A, Maltby K, Bush M, Tao WX, Napolitano A, Skeggs AL, Brooke AC, Cheke L, Clayton NS, Sadaf Farooqi I, O'Rahilly S, Waterworth D, Song K, Hosking L, Richards DB, Fletcher PC, Bullmore ET (2013) Effects of the mu-opioid receptor antagonist GSK1521498 on hedonic and consummatory eating behaviour: a proof of mechanism study in binge-eating obese subjects. Mol Psychiatry 18:1287-1293. CrossRef Medline

Zubieta JK, Dannals RF, Frost JJ (1999) Gender and age influences on human brain mu-opioid receptor binding measured by PET. Am J Psychiatry 156:842-848. CrossRef Medline

Zubieta JK, Smith YR, Bueller JA, Xu Y, Kilbourn MR, Jewett DM, Meyer CR, Koeppe RA, Stohler CS (2001) Regional mu opioid receptor regulation of sensory and affective dimensions of pain. Science 293:311-315. CrossRef Medline 